\section{Protein phosphatase PP1 is required for normal DNA methylation in Neurospora}

\author{
Keyur K. Adhvaryu and Eric U. Selker ${ }^{1}$ \\ Institute of Molecular Biology, University of Oregon, Eugene, \\ Oregon 97403, USA
}

Covalent modifications of histones integrate intracellular and extracellular cues to regulate the genome. H3 Lys 9 methylation (H3K9me) can direct heterochromatin formation and DNA methylation, while phosphorylation of H3 Ser 10 (H3S10p) drives gene activation and chromosome condensation. To examine the relationship between H3S10p, H3K9me, and DNA methylation in Neurospora crassa, we built and tested mutants of the putative H3S10 phosphatase, PP1. A PP1-impaired mutant showed increased $\mathrm{H} 3 \mathrm{S10} \mathrm{p}$ and selective reduction of methylation of H3K9 and DNA. Similarly, amino acid substitutions of $\mathrm{H} 3 \mathrm{S10}$ abolished methylation of H3K9 and DNA. Thus, H3S10 dephosphorylation by PP1 is required for DNA methylation of some loci.

Supplemental material is available at http://www.genesdev.org.

Received September 8, 2008; revised version accepted November 4, 2008.

A key feature of eukaryotic genomes is their segregation into active and inactive components, generally referred to as euchromatin and heterochromatin, respectively. The state of chromatin influences genetic processes including replication, chromosome segregation, transcription, repair, and recombination. In the last decade there has been an explosion of evidence suggesting that histone modifications play important roles in functioning of the associated DNA. Heterochromatin and euchromatin show different histone modifications (Strahl and Allis 2000; Jenuwein and Allis 2001). For example, methylation of Lys 9 on $\mathrm{H} 3$ (H3K9me) is involved in the establishment of heterochromatin, DNA methylation, and gene silencing. In contrast, the neighboring residue, Ser 10 (H3S10) is subject to phosphorylation by a number of kinases, either in response to environmental signals to activate genes, or in response to internal cues in the cell to drive the events associated with chromosome condensation and segregation during mitosis and meiosis (Prigent and Dimitrov 2003; Nowak and Corces 2004; Johansen and Johansen 2006).

Effects of H3S10p may be mediated by its influence on methylation of $\mathrm{H} 3 \mathrm{~K} 9$, which in turn can control other processes, such as DNA methylation in Neurospora (Tamaru and Selker 2001). Structural studies showed

[Keywords: Neurospora crassa; DNA methylation; protein phosphatase PP1; Histone H3 Ser 10 phosphorylation; histone H3 mutation] ${ }^{1}$ Corresponding author.

E-MAIL selker@molbio.uoregon.edu; FAX (541) 346-5891.

Article is online at http://www.genesdev.org/cgi/doi/10.1101/gad.1738008. that the Neurospora H3K9 methyltransferase DIM-5 directly interacts with H3S10, suggesting that S10 phosphorylation may influence methylation of $\mathrm{K} 9$ (Zhang et al. 2003), and mutation of a DIM-5 residue that interacts with S10 (D209) abolishes its methyltransferase activity (Rathert et al. 2008). Moreover, phosphorylation of Ser 10 in an $\mathrm{H} 3$ peptide substrate prevents the activity of H3K9 methyltransferases that have been tested in vitro, SUV39H1, Clr4, and DIM-5 (Rea et al. 2000; Nakayama et al. 2001; our unpublished results). H3S10 phosphorylation is also known to influence the binding of effector proteins such as HP1, which recognizes methylation of $\mathrm{H} 3 \mathrm{~K} 9$ to direct heterochromatin formation (Fischle et al. 2005; Hirota et al. 2005). This forms the basis of a "methyl-phospho switch" in which H3S10 phosphorylation by Aurora B at the onset of mitosis causes the dissociation of heterochromatin protein HP1 from pericentric heterochromatin (Fischle et al. 2005; Hirota et al. 2005). Similarly, in fission yeast, H3S10 phosphorylation by the Aurora kinase Ark1 causes a dissociation of the HP1 homolog, Swi6, from heterochromatin /Chen et al. 2008; Kloc et al. 2008). Reassociation of HP1 with chromatin can occur after dephosphorylation of H3S10p (Fischle et al. 2005; Hirota et al. 2005; Chen et al. 2008). Protein phosphatase PP1 is believed to be the H3S10 phosphatase in Saccharromyces cerevisiae and Caenorhabditis elegans (Hsu et al. 2000; Murnion et al. 2001) but no studies have addressed its possible role in heterochromatin formation. Intriguingly, a point mutation in PP1 (Gly200Ser/Asp) results in suppression of position effect variegation (PEV) in Drosophila suppressor Su-var(3)-6 (Dombradi and Cohen 1992).

Because methylation of $\mathrm{H} 3 \mathrm{~K} 9$ is critical for DNA methylation in N. crassa and some other systems, we sought to investigate the possible role of H3S10 phosphorylation in H3K9 and DNA methylation in Neurospora. DNA methylation in this filamentous fungus is an outcome of a genome defense mechanism, repeat-induced point mutation (RIP) (Selker 1990; Galagan and Selker 2004). During premeiosis, the RIP machinery recognizes duplications and peppers them with C:G to T:A mutations. In general, the remaining cytosines of mutated sequences are subject to methylation by the DNA methyltransferase (DNMTase) DIM-2 (Kouzminova and Selker 2001). Indeed, most DNA methylation in Neurospora is found in relics of RIP (Galagan et al. 2003; Selker et al. 2003). Cytosine DNA methylation depends on H3K9 methylation by DIM-5 (Tamaru and Selker 2001; Tamaru et al. 2003). The resulting trimethyl mark (H3K9me3) is read by the heterochromatin protein HP1, which directly interacts with DIM-2 (Freitag et al. 2004a; Honda and Selker 2008). Establishment and maintenance of DNA methylation does not require the RNAi machinery (Freitag et al. 2004b). Here we show that dephosphorylation of H3S10 is a prerequisite for establishment of H3K9 methylation. We created a partial loss-offunction mutant in the $p p p-1$ gene $\left(p p p-1^{R I P 2}\right)$ and generated substitutions of the target of PP1, H3S10 $\left(h H 3^{S 1 O A / G / E}\right)$. Our in vivo results demonstrate that dephosphorylation of H3S10 by PP1 is required for normal H3K9 methylation and DNA methylation in Neurospora. 
A

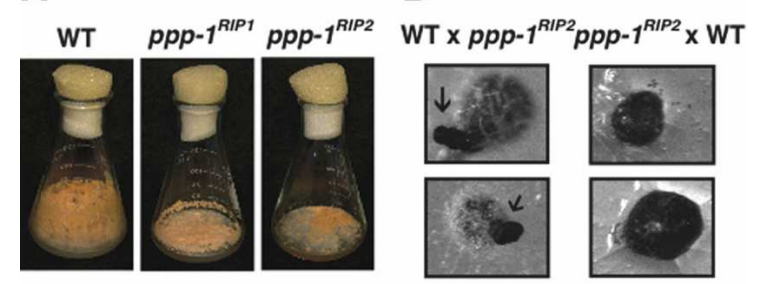

C

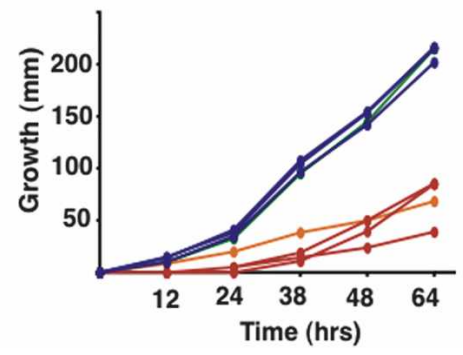

Figure 1. PP1 is required for normal vegetative and sexual development. (A) ppp-1 mutants have reduced aerial hyphae and conidia. Wild type (N150), $p p p-1^{R I P 1}(\mathrm{~N} 3482)$, and $p p p-1^{R I P 2}(\mathrm{~N} 3468)$ after $7 \mathrm{~d}$ of growth at $32^{\circ} \mathrm{C}$ on Vogel's $\mathrm{N}$ medium containing $1.5 \%$ sucrose. (B) Reciprocal crosses of wild type (N150) with $p p p-1^{\text {RIP2 }}$ (N3468) on synthetic crossing medium containing $0.1 \%$ sucrose. The female parent was inoculated $4 \mathrm{~d}$ before fertilization. Photographs were taken after $20 \mathrm{~d}$ at $25^{\circ} \mathrm{C}$. When wild type was used as the female, development was normal and perithecia formed beaks (arrows). When $p p p-1^{R I P 2}$ was used as the female, beaks were not formed and perithecia burst to release ascospores on the agar surface. $(C)$ Reduced growth rates of the $p p p-1$ mutants. Linear growth rates were measured in "race tubes" for wild type (N150, green), ppp-1 RIP1 $^{2}$ (N3482, orange), and siblings from a cross of wild type with ppp$1^{\text {RIP2 }}$ (three wild-type progeny N3463, N3464, and N3465 [blue] and three mutant progeny N3466, N3467, and N3468 [red]). Points represent averaged measurements from three tubes.

\section{Results and Discussion}

PP1 activity is essential for growth and development of Neurospora

As a first step to explore the effect of H3S10 phoshorylation on DNA methylation we generated and examined mutants in the putative H3S10 phosphatase, PP1. Studies with a partial loss-of-function mutant obtained previously $\left(p p p-1^{R I P 1}\right)$ suggested that PP1 may be essential in Neurospora (Yang et al. 2004). We confirmed this (see below) but managed to use RIP to make a strain (his$\left.3^{+}:: P c c g-1-p p p-1^{+}-s g f p^{+} ; p p p-1^{R I P 2}\right)$ with a greater deficiency for PP1. In this mutant strain the endogenous ppp-1 allele is expected to be a null due to the presence of two nonsense and multiple missense mutations (Supplemental Material). This strain also has a GFP tagged copy of ppp-1 gene at an ectopic location (his-3) driven by the $c c g-1$ promoter. The presence of the bulky GFP tag and expression under a heterologous promoter caused incomplete complementation of the null mutant, leading to a partial loss-of-function phenotype. Hereafter, we will refer to this mutant strain as $p p p-1^{\text {RIP2 }}$. Both the mutants grew slower than wild type, had reduced aerial hyphae, and produced fewer conidia (vegetative spores) (Fig. 1A,C). They were also defective in sexual development (Fig. 1B). These defects were rescued upon complementation of the mutant with the wild-type allele (Supplemental Fig. 1; data not shown). We were un- able segregate this partially complementing wild-type copy from the RIP generated null allele $\left(p p p-1^{\text {RIP2 }}\right)$ in crosses, indicating that PP1 is essential in Neurospora (Supplemental Material; data not shown). This conclusion was confirmed by finding that it was impossible to isolate viable progeny bearing a deletion of this gene from a sheltered heterokaryotic knockout strain generated by the Neurospora Knockout Project (Colot et al. 2006).

PP1 is responsible for the dephosphorylation of H3S10 and influences methylation of H3K9 and DNA

To determine if PP1 is responsible for the dephosphorylation of H3S10 in Neurospora, we performed Western analyses on nuclear extracts using antibodies that recognize specific histone H3 modifications. Very low levels of $\mathrm{H} 3 \mathrm{~S} 10$ phosphorylation were observed in the wildtype strain, but substantial phosphorylation was found in the mutants, indicating that PP-1 is indeed important in the control of S10 phosphorylation (Fig. 2A). Despite $p p p-1^{R I P 2}$ being maintained in a PP1-GFP background that provided some PP1 activity, the $p p p-1^{R I P 2}$ strain showed greater phosphorylation than the leaky $p p p-1^{R I P 1}$ mutant. Western analysis did not show substantial

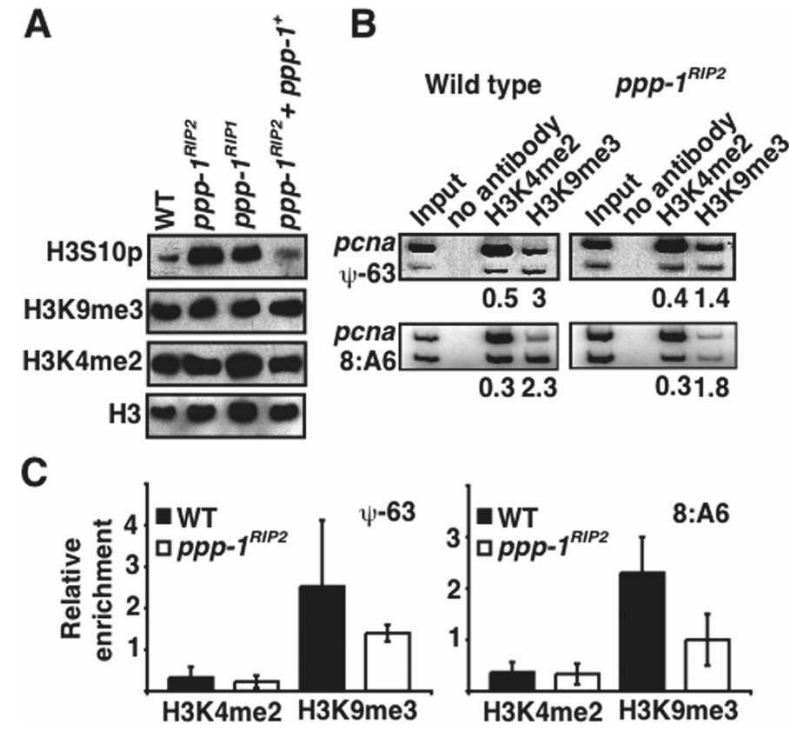

Figure 2. Increased $\mathrm{H} 3 \mathrm{~S} 10$ phosphorylation leads to a decrease in $\mathrm{H} 3 \mathrm{~K} 9$ methylation in genomic regions that loose DNA methylation in ppp-1 mutants. (A) Increased levels of H3S10 phosphorylation in ppp-1 mutants. Nuclear extracts from wild type (N150), ppp-1 $1^{\text {RIP2 }}$ (N3468), ppp-1 $1^{R I P 1}(\mathrm{~N} 3482)$, and complemented strain (ppp$1^{\text {RIP2 }}+$ ppp $-1^{+} ; \mathrm{N} 3470$ ) were analyzed for $\mathrm{H} 3 \mathrm{~K} 4 \mathrm{me} 2, \mathrm{H} 3 \mathrm{~K} 9 \mathrm{me} 3$, and H3S10p by Western blotting. Loading of proteins was monitored by a Western blot for histone H3. (B) Reduction in H3K9me3 at genomic loci that loose DNA methylation in $p p p-1^{R I P 2}$. ChIP was performed with wild type (N150, left panel) and ppp-1 $1^{\text {RIP2 }}$ (N3468, right panel) using antibodies to immunoprecipitate either H3K4me2 or H3K9me3. Primer pairs were used in duplex PCRs to amplify an unmethylated region (pcna) and methylated regions ( $\psi-63$ or 8:A6) (Tamaru et al. 2003). The relative enrichment of the modification (H3K4me2 or H3K9me3) at methylated regions compared with that of an unmethylated region ( $\psi-63 /$ pcna or 8:A6/pcna) is indicated. $(C)$ Quantitation of reduced $\mathrm{H} 3 \mathrm{~K} 9 \mathrm{me} 3$ at genomic loci that lost DNA methylation. Data were obtained from duplex PCRs to amplify an unmethylated region (pcna) with two methylated regions $(\psi-63$ or 8:A6) (Supplemental Fig. 2). 


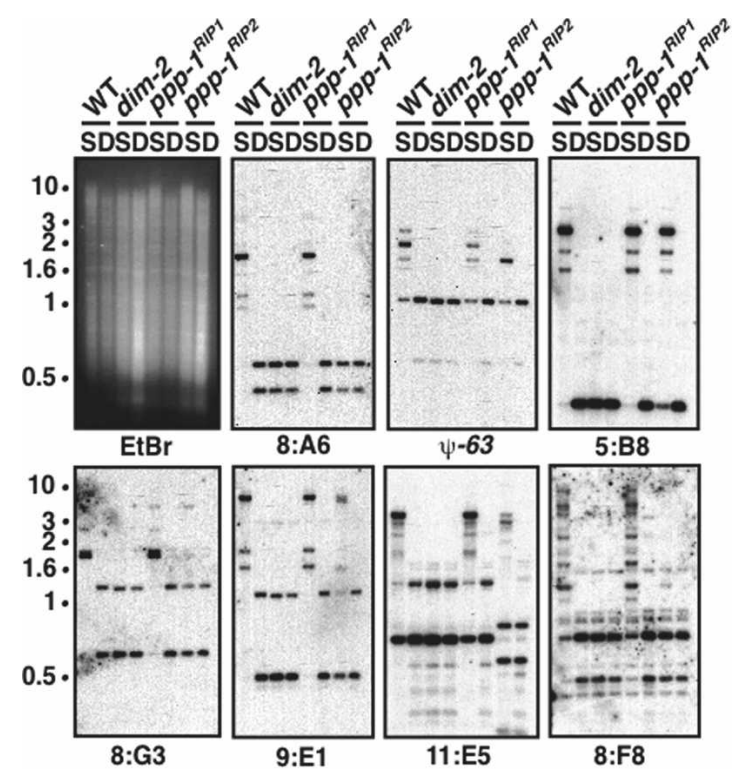

Figure 3. PP1 is required for normal DNA methylation. Loss of DNA methylation in the $p p p-1$ mutants. DNA samples from wild type (N150), dim-2 (N1860), ppp-1 $1^{R I P 1}(\mathrm{~N} 3482)$, and ppp-1 $1^{R I P 2}$ (N3468) were digested with methylation-sensitive and methylationinsensitive isoschizomers, Sau3AI (S) or DpnII (D), respectively, and used in Southern hybridizations with probes for methylated regions (8:A6, 4-63, 5:B8, 8:G3, 9:E1, 11:E5, and 8:F8) (Selker et al. 2003). Blots were stripped and reprobed for an unmethylated region (set-1) (K. Adhvaryu and E. Selker, unpubl.) to confirm complete digestion of DNA (data not shown). The ethidium bromide (EtBr)-stained gel is shown revealing equivalent patterns with Sau3AI- and DpnIIdigested dim-2 DNA because this strain is completely defective in DNA methylation (Kouzminova and Selker 2001). Position of the size standards (in kilobases) are shown.

changes in global levels of methylation at $\mathrm{H} 3 \mathrm{~K} 4$ or $\mathrm{K} 9$ (Fig. 2A) but chromatin immunoprecipitation (ChIP) revealed reduction of $\mathrm{H} 3 \mathrm{~K} 9 \mathrm{me} 3$ in regions of DNA methylation (Fig. 2B,C; Supplemental Fig. 2).

Because trimethylation of $\mathrm{H} 3 \mathrm{~K} 9$ is read by $\mathrm{HP} 1$ to direct DNA methylation (Freitag et al. 2004a), we expected that reduction in $\mathrm{H} 3 \mathrm{~K} 9$ methylation would cause a corresponding reduction of DNA methylation. To test this possibility, we analyzed DNA methylation in the $p p p-1$ mutants by Southern hybridization. Consistent with the regional reduction of $\mathrm{H} 3 \mathrm{~K} 9 \mathrm{me} 3$, we observed a loss of DNA methylation in the PP1 mutants at some chromosomal regions (Fig. 3). Interestingly, unlike the case in some mutants, such as dim-2 (which encodes the DNMTase), loss of DNA methylation was not complete in the ppp-1 mutants (Fig. 3); we observed a partial or complete loss of methylation in eight of 10 regions tested, suggesting that some methylated regions of the genome require PP1 while others do not. Alternatively, it is possible that the residual level of PP1 required to sustain viability is sufficient to support the low levels of DNA methylation. Not surprisingly, the loss of DNA methylation was more pronounced in the $p p p-1^{R I P 2}$ strain than in $p p p-1^{R I P 1}$ strain (Fig. 2). Introduction of a wild-type copy of $p p p-1$ at an ectopic location (his-3) resulted in complementation of the mutant phenotypes (Fig. 2; Supplemental Fig. 1). Normal levels of H3K9me3 were found in the regions that retain DNA methylation in the $p p p-1^{R I P 2}$ strain (Supplemental Fig. 3).
Mutants with substitutions of H3 S10 are viable but show developmental defects and are defective in DNA methylation

In principle, the effect of PP1 on methylation of H3K9 and DNA could be indirect. To determine if residue 10 of $\mathrm{H} 3$ plays a role in histone and DNA methylation we tested the effect of amino acid substitutions at this position. Neurospora harbors just one histone H3 gene (Hays et al. 2002), facilitating tests of mutations in this gene. Using RIP, we generated a nonfunctional allele of H3 that has two nonsense and multiple missense mutations $\left(h H 3^{R I P 1}\right)$ (Supplemental Material). An additional copy of $\mathrm{H} 3$ with a serine to alanine substitution at residue $10\left(h H 3^{S 1 O A}\right)$ was introduced at an ectopic position (his-3), which successfully sheltered this null mutation (his- $\left.3^{+}:: h H 3^{S 1 O A} ; h H 3^{R I P 1}\right)$. We also successfully introduced alleles in which $\mathrm{S} 10$ was replaced by glycine or glutamic acid $\left(h H 3^{S 1 O G}, h H 3^{S 1 O E}\right)$. In these strains all histone H3 had Ser 10 mutated (Fig. 4A). These histone mutants grew slower than wild type, produced conidia sparsely, and were female sterile (Supplemental Fig. 4; data not shown). A loss of $\mathrm{H} 3 \mathrm{~K} 9 \mathrm{me} 3$ was observed in
A

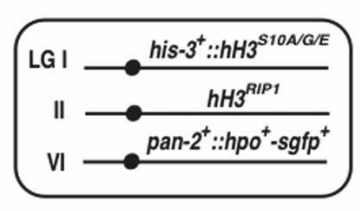

B

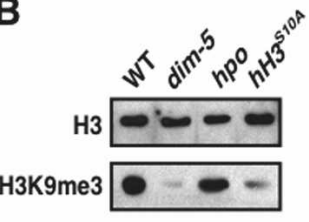

C

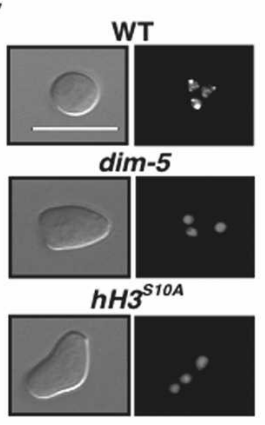

D

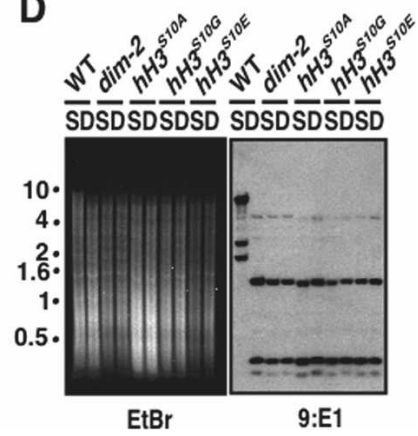

Figure 4. Mutation of H3S10 phenocopies ppp-1. (A) Schematic of histone $\mathrm{H} 3$ mutant genotypes. A null allele of $h H 3$ at the endogenous locus ( $h H 3^{R I P 1}$ ) (Supplemental Material) was combined with the desired substitutions $\left(h H 3^{S 1 O A / G / E}\right)$ at his-3. These strains also have HP1-GFP (Freitag et al. 2004a). (B) Global loss of H3K9me3 was observed in the $h H 3^{S 1 O A}$ mutant. Western blots were performed with $\sim 100 \mu \mathrm{g}$ of nuclear proteins from wild-type (WT; N150), dim-5 (N2264), hpo (N2532), or $h H 3^{S 10 A}$ (N3474) strains using antibodies against H3K9me3. The hpo mutant showed an apparently normal level of H3K9me3. The faint bands in the dim-5 and $h H 3^{S 10 A}$ mutants presumably reflect background signals due to cross-reactivity of the antibody (Tamaru et al. 2003; Collins et al. 2005). Levels of H3 were analyzed to evaluate loading. $(C)$ HP1 localization to heterochromatin is lost in the $h H 3^{S 10 A}$ mutant. Visualization of GFPtagged HP1 in nuclei of germinating conidia is shown for wild-type (N2534), dim-5 (N2542), and $h H 3^{\text {SIOA }}$ (N3481) strains. Bar, $10 \mu \mathrm{m}$. (D) Loss of DNA methylation in $h H 3$ mutants $\left[h H 3^{\text {S1OA }}\right.$ (N3474), $h H 3^{\text {S1OG }}(\mathrm{N} 3477)$, and $h H 3^{\text {S1OE }}$ (N3478)]. Southern blots of DNA (of hH3 mutants and wild type [N150] and dim-2 [N1860] controls) digested with Sau3AI (S) or DpnII (D) and probed for 9:E1and other methylated regions (not shown). The ethidium bromide (EtBr)stained gel shows equivalent patterns with Sau3AI-and DpnII-digested hH3 mutant DNA, as with dim-2, indicative of loss of DNA methylation. 


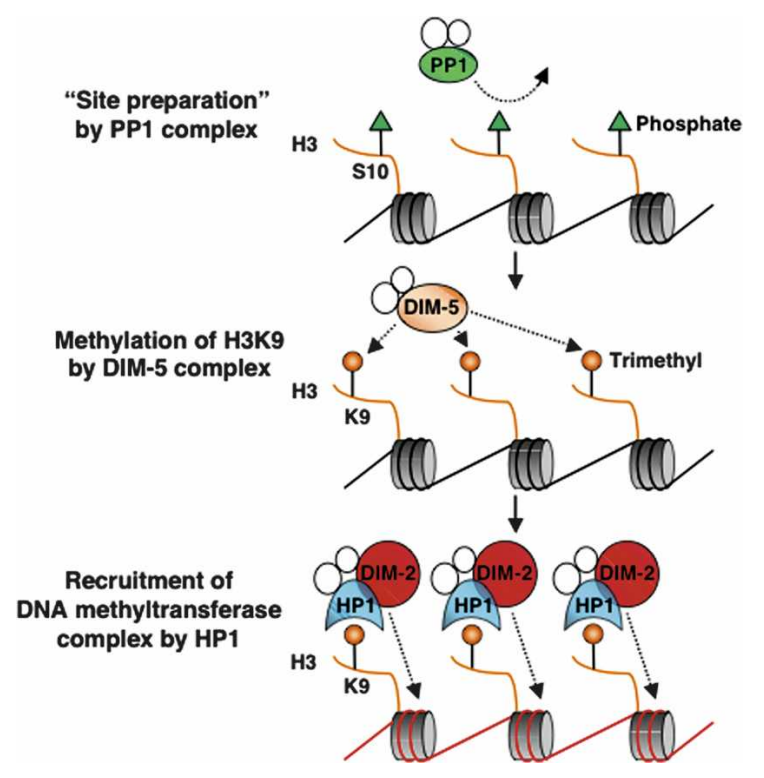

Figure 5. Model for role of protein phosphatase PP1 in establishment of DNA methylation. Unknown regulatory factor(s) recruit the catalytic subunit PP1 to the chromatin causing dephosphorylation of H3S10. This permits methylation of H3K9 by DIM-5. HP1 recognizes and binds this trimethyl mark, setting the stage for subsequent events that lead to methylation of DNA by DIM-2. Open ovals indicate putative unknown factors in various complexes.

these mutants using two independent preparations of anti-H3K9me3 antibodies (Fig. 4B; Supplemental Fig. 5; data not shown), suggesting that $\mathrm{S} 10$ is indeed important for K9 methylation. Fluorescence microscopy showed that, as expected, HP1-GFP localization was also perturbed by mutation of S10, as by mutation of DIM- 5 itself (Fig. 4C). Most importantly, the loss of H3K9me3 and mislocalization of HP1 was associated with a complete loss of DNA methylation in these strains (Fig. 4D). The fact that this effect is even more striking than that observed in the ppp-1 mutants (Figs. 3, 4D) may reflect the importance of Ser 10 in recognition of H3 by DIM-5 (K.K. Adhvaryu, E. Berge, H. Tamaru, M. Freitag, and E.U. Selker, in prep.). It is interesting that, unlike PP1, S10 does not appear to be essential since S10 substitution strains are viable. Similar substitutions were found to cause defects in chromosome condensation and segregation in Tetrahymena, S. cerevisiae, and Schizosaccharomyces pombe (Wei et al. 1998; Hsu et al. 2000; Mellone et al. 2003).

Accurate partitioning of the genome into domains of euchromatin and heterochromatin depends on the regulation of H3S10 phosphorylation. For example, in Drosophila the activity of the H3S10 kinase JIL-1 helps maintain the distinction between these euchromatic and heterochromatic domains by preventing ectopic H3K9 methylation and HP1 binding (Zhang et al. 2006; Bao et al. 2007). H3S10 phosphorylation is also required for the faithful propagation of heterochromatin during the cell cycle. In the fission yeast, increased H3S10 phosphorylation caused by Aurora kinase Ark1 during $S$ phase drives the transcription of repeats in these regions. This results in the generation of small RNAs that nucleate the formation of heterochromatin by recruiting the RNAi machinery and the ClrC complex (Chen et al. 2008; Kloc et al. 2008; Zhang et al. 2008). Decreased
H3S10 phosphorylation allows reassociation of HP1 with chromatin (Chen et al. 2008). A failure to remove the phosphate group from S10 would prevent this reassociation of HP1 with chromatin. Thus, regulated dephosphorylation of H3S10 appears to be important for maintenance and propagation of heterochromatin.

Although H3S10 phosphatase activity has been attributed to PP1 (Hsu et al. 2000; Murnion et al. 2001), its role in formation of heterochromatin was not previously established. Using a partial loss-of-function mutant, we demonstrate that PP1-dependent dephosphorylation of $\mathrm{H} 3 \mathrm{~S} 10$ is required prior to methylation of H3K9 by DIM5 , binding of HP1 and DNA methylation. The elevated global level of H3S10 phosphorylation in this mutant suggests that PP1 is the major H3S10 phosphatase in Neurospora. Increased H3S10 phosphorylation could cause disassociation of HP1 from heterochromatin leading to a loss of DNA methylation, but considering that a S10A replacement or phosphorylation of S10 results in a loss of DIM-5 activity in vitro (K.K. Adhvaryu, E. Berge, H. Tamaru, M. Freitag, and E.U. Selker, in prep.) it seems likely that H3S10 phosphorylation interferes with establishment of H3K9 methylation leading to a loss of DNA methylation. As noted above, other H3K9 methyltransferases including SUV39H1 and Clr4 are similarly sensitive to H3S10 phosphorylation in vitro (Rea et al. 2000; Nakayama et al. 2001).

Based on our observations, we propose a model for the role of PP1 in the establishment of DNA methylation in Neurospora (Fig. 5). PP1 is recruited to chromatin by an unidentified regulatory protein, causing dephosphorylation of H3S10, and this prepares the site for DIM-5 to methylate the neighboring K9. The trimethyl mark laid down by the DIM-5 is read by HP1 to directly recruit the DNMTase DIM-2 leading to DNA methylation (Honda and Selker 2008). It will be interesting to learn what targets various chromosomal regions for phosphorylation and dephosphorylation. Regulators of PP1 such as the "14-3-3" group of proteins or Repo-Man may be involved (Trinkle-Mulcahy et al. 2006; Winter et al. 2008). Future work will clarify the emerging connections between cell cycle-dependent phosphorylation of H3S10, methylation of H3K9, and DNA methylation.

\section{Materials and methods}

\section{Neurospora strains and methods}

Strains used in this study are listed in Supplemental Table 1 and were grown, maintained and crossed according to standard procedures (Davis 2000). Generation of $p p p-1^{R I P 2}$ and histone H3 Ser 10 substitutions are described in the Supplemental Material. For isolation of genomic DNA, strains were grown with shaking in Vogel's minimal medium $\mathrm{N}$ with $1.5 \%$ sucrose and appropriate supplements for $3 \mathrm{~d}$ at $32^{\circ} \mathrm{C}$, and DNA was isolated essentially as described previously (Irelan et al. 1993).

\section{Genomic Southern analyses}

Approximately $1 \mu \mathrm{g}$ DNA was digested overnight with 3-5 U of restric tion enzyme, fractionated in $0.8 \%-1.0 \%$ agarose gels, and transferred to nylon membranes and hybridized with probes prepared by random oligomer priming (Feinberg and Vogelstein 1983) as described previously (Selker and Stevens 1987).

\section{Western blotting}

Nuclei were isolated by an adaptation of the method of Baum and Giles (1986). The following reagents were added to all the buffers: $1 \mathrm{mM}$ sodium butyrate, $1 \mu \mathrm{M}$ Trichostatin A, $1 \mu \mathrm{M}$ PMSF, $3 \mathrm{mM}$ DTT, $10 \mathrm{mM}$ sodium fluoride, $1 \mathrm{mM}$ sodium vanadate, $0.1 \%$ phosphatase inhibitor 
cocktail (Sigma, P2850), and $1 \mu \mathrm{M}$ each of leupeptin (Roche, 11034626001), pepstatin (Roche, 11524488001), and E-64 (Roche, 11585681001 ). Western blotting was performed with $\sim 100 \mu \mathrm{g}$ of nuclear protein per sample as described previously (Tamaru et al. 2003). The following antibodies were used: $\alpha-\mathrm{H} 3$ (Abcam, \#1791), $\alpha-\mathrm{H} 3 \mathrm{~K} 4 \mathrm{me} 2$ (Upstate Biotechnologies, 07-030), $\alpha-\mathrm{H} 3 \mathrm{~K} 9 \mathrm{me} 3$ (Cowell et al. 2002), and $\alpha-H 3 S 10 p$ (Mitosis marker; Upstate Biotechnologies, 06-570). All antibodies were used at a dilution of 1:5000. HRP-conjugated goat antibody against rabbit IgG was used to detect antibody-peptide complexes by chemiluminescene (Pierce).

\section{ChIP}

ChIP experiments were performed as described previously (Adhvaryu et al. 2005) with the following antibodies: $\alpha$-H3K4me2 (Upstate Biotechnologies, 07-030) and $\alpha$-H3K9me3 (Cowell et al. 2002). To calculate relative enrichment band intensities were quantified using phosphor imager and the ImageQuant software (Molecular Dynamics). The values for methylated regions were divided by the values for the unmethylated region and normalized to signals of total input.

\section{Microscopy}

Suspensions of conidia were germinated on Vogel's $\mathrm{N}$ agar medium containing $1.5 \%$ sucrose and the required supplements in Petri plates for $2 \mathrm{~h}$ at $30^{\circ} \mathrm{C}$. Pieces of agar with germinating conidia were cut from plates and placed on glass slides, flooded with a few drops of liquid medium, and then overlayed with coverslips. Bright-field and fluorescence images were collected using a Zeiss Axioplan 2 Imaging system with a 10× objective and a 100x oil immersion lens. Images were processed using the Axiovision (version 4.6.3) and Adobe Photoshop CS (version 8) software. About 100 cells were examined for each sample.

\section{Acknowledgments}

We thank Dr. Yi Liu (University of Texas Southwest Medical Center) for the $p p p-1^{R I P 1}$ strain. We also thank Zachary Lewis, Shinji Honda, and Tamir Khalfallah for helpful suggestions on the manuscript. This work was supported by NIH grant GM025690-22 to E.U.S. K.K.A was supported partly by a fellowship from the American Heart Association (02275370Z)

\section{References}

Adhvaryu, K.K., Morris, S.A., Strahl, B.D., and Selker, E.U. 2005. Methylation of histone $\mathrm{H} 3$ lysine 36 is required for normal development in Neurospora crassa. Eukaryot. Cell 4: 1455-1464.

Bao, X., Deng, H., Johansen, J., Girton, J., and Johansen, K.M. 2007. Lossof-function alleles of the JIL-1 histone H3S10 kinase enhance position-effect variegation at pericentric sites in Drosophila heterochromatin. Genetics 176: 1355-1358.

Baum, J.A. and Giles, N.H. 1986. DNase I hypersensitive sites within the inducible qa gene cluster of Neurospora crassa. Proc. Natl. Acad. Sci. 83: 6533-6537.

Chen, E.S., Zhang, K., Nicolas, E., Cam, H.P., Zofall, M., and Grewal, S.I. 2008. Cell cycle control of centromeric repeat transcription and heterochromatin assembly. Nature 451: 734-737.

Collins, R.E., Tachibana, M., Tamaru, H., Smith, K.M., Jia, D., Zhang, X., Selker, E.U., Shinkai, Y., and Cheng, X. 2005. In vitro and in vivo analyses of a Phe/Tyr switch controlling product specificity of histone lysine methyltransferases. J. Biol. Chem. 280: 5563-5570.

Colot, H.V., Park, G., Turner, G.E., Ringelberg, C., Crew, C.M., Litvinkova, L., Weiss, R.L., Borkovich, K.A., and Dunlap, J.C. 2006. A high-throughput gene knockout procedure for Neurospora reveals functions for multiple transcription factors. Proc. Nat1. Acad. Sci. 103: 10352-10357.

Cowell, I.G., Aucott, R., Mahadevaiah, S.K., Burgoyne, P.S., Huskisson, N., Bongiorni, S., Prantera, G., Fanti, L., Pimpinelli, S., Wu, R., et al. 2002. Heterochromatin, HP1 and methylation at lysine 9 of histone H3 in animals. Chromosoma 111: 22-36.

Davis, R.H. 2000. Neurospora: Contributions of a model organism. Oxford University Press, New York.

Dombradi, V. and Cohen, P.T. 1992. Protein phosphorylation is involved in the regulation of chromatin condensation during interphase. FEBS
Lett. 312: 21-26.

Feinberg, A.P. and Vogelstein, B. 1983. A technique for radiolabeling DNA restriction endonuclease fragments to high specific activity (I). Anal. Biochem. 132: 6-13.

Fischle, W., Tseng, B.S., Dormann, H.L., Ueberheide, B.M., Garcia, B.A., Shabanowitz, J., Hunt, D.F., Funabiki, H., and Allis, C.D. 2005. Regulation of HP1-chromatin binding by histone $\mathrm{H} 3$ methylation and phosphorylation. Nature 438: 1116-1122.

Freitag, M., Hickey, P.C., Khlafallah, T.K., Read, N.D., and Selker, E.U. 2004a. HP1 is essential for DNA methylation in Neurospora. Mol. Cell 13: 427-434.

Freitag, M., Lee, D.W., Kothe, G.O., Pratt, R.J., Aramayo, R., and Selker, E.U. 2004b. DNA methylation is independent of RNA interference in Neurospora. Science 304: 1939.

Galagan, J.E. and Selker, E.U. 2004. RIP: The evolutionary cost of genome defense. Trends Genet. 20: 417-423.

Galagan, J.E., Calvo, S.E., Borkovich, K.A., Selker, E.U., Read, N.D., Jaffe, D., FitzHugh, W., Ma, L.J., Smirnov, S., Purcell, S., et al. 2003. The genome sequence of the filamentous fungus Neurospora crassa. $\mathrm{Na}$ ture 422: 859-868.

Hays, S.M., Swanson, J., and Selker, E.U. 2002. Identification and characterization of the genes encoding the core histones and histone variants of Neurospora crassa. Genetics 160: 961-973.

Hirota, T., Lipp, J.J., Toh, B.H., and Peters, J.M. 2005. Histone H3 serine 10 phosphorylation by Aurora B causes HP1 dissociation from heterochromatin. Nature 438: 1176-1180.

Honda, S. and Selker, E.U. 2008. Direct interaction between DNA methyltransferase DIM-2 and HP1 is required for DNA methylation in Neurospora. Mol. Cell. Biol. 28: 6044-6055.

Hsu, J.Y., Sun, Z.W., Li, X., Reuben, M., Tatchell, K., Bishop, D.K., Grushcow, J.M., Brame, C.J., Caldwell, J.A., Hunt, D.F., et al. 2000. Mitotic phosphorylation of histone $\mathrm{H} 3$ is governed by Ipll/aurora kinase and Glc7/PP1 phosphatase in budding yeast and nematodes. Cell 102: 279-291.

Irelan, J., Miao, V., and Selker, E.U. 1993. Small scale DNA preps for Neurospora crassa. Fungal Genet. Newsl. 40: 24.

Jenuwein, T. and Allis, C.D. 2001. Translating the histone code. Science 293: $1074-1080$.

Johansen, K.M. and Johansen, J. 2006. Regulation of chromatin structure by histone H3S10 phosphorylation. Chromosome Res. 14: 393-404.

Kloc, A., Zaratiegui, M., Nora, E., and Martienssen, R. 2008. RNA interference guides histone modification during the $\mathrm{S}$ phase of chromosomal replication. Curr. Biol. 18: 490-495.

Kouzminova, E.A. and Selker, E.U. 2001. Dim-2 encodes a DNA-methyltransferase responsible for all known cytosine methylation in Neurospora. EMBO T. 20: 4309-4323.

Mellone, B.G., Ball, L., Suka, N., Grunstein, M.R., Partridge, J.F., and Allshire, R.C. 2003. Centromere silencing and function in fission yeast is governed by the amino terminus of histone H3. Curr. Biol. 13: $1748-1757$.

Murnion, M.E., Adams, R.R., Callister, D.M., Allis, C.D., Earnshaw, W.C., and Swedlow, J.R. 2001. Chromatin-associated protein phosphatase 1 regulates aurora-B and histone $\mathrm{H} 3$ phosphorylation. J. Biol. Chem. 276: 26656-26665.

Nakayama, J., Rice, J.C., Strahl, B.D., Allis, C.D., and Grewal, S.I. 2001. Role of histone H3 lysine 9 methylation in epigenetic control of heterochromatin assembly. Science 292: 110-113.

Nowak, S.J. and Corces, V.G. 2004. Phosphorylation of histone H3: A balancing act between chromosome condensation and transcriptional activation. Trends Genet. 20: 214-220.

Prigent, C. and Dimitrov, S. 2003. Phosphorylation of serine 10 in histone H3, what for? J. Cell Sci. 116: 3677-3685.

Rathert, P., Zhang, X., Freund, C., Cheng, X., and Jeltsch, A. 2008. Analysis of the substrate specificity of the Dim-5 histone lysine methyltransferase using peptide arrays. Chem. Biol. 15: 5-11.

Rea, S., Eisenhaber, F., O'Carroll, D., Strahl, B.D., Sun, Z.W., Schmid, M., Opravil, S., Mechtler, K., Ponting, C.P., Allis, C.D., et al. 2000. Regulation of chromatin structure by site-specific histone H3 methyltransferases. Nature 406: 593-599.

Selker, E.U. 1990. Premeiotic instability of repeated sequences in Neurospora crassa. Annu. Rev. Genet. 24: 579-613.

Selker, E.U. and Stevens, J.N. 1987. Signal for DNA methylation associated with tandem duplication in Neurospora crassa. Mol. Cell. Biol. 


\section{Adhvaryu and Selker}

7: 1032-1038.

Selker, E.U., Tountas, N.A., Cross, S.H., Margolin, B.S., Murphy, J.G., Bird, A.P., and Freitag, M. 2003. The methylated component of the Neurospora crassa genome. Nature 422: 893-897.

Strahl, B.D. and Allis, C.D. 2000. The language of covalent histone modifications. Nature 403: 41-45.

Tamaru, H. and Selker, E.U. 2001. A histone H3 methyltransferase controls DNA methylation in Neurospora crassa. Nature 414: 277-283.

Tamaru, H., Zhang, X., McMillen, D., Singh, P.B., Nakayama, J., Grewal, S.I., Allis, C.D., Cheng, X., and Selker, E.U. 2003. Trimethylated lysine 9 of histone H3 is a mark for DNA methylation in Neurospora crassa. Nat. Genet. 34: 75-79.

Trinkle-Mulcahy, L., Andersen, J., Lam, Y.W., Moorhead, G., Mann, M., and Lamond, A.I. 2006. Repo-Man recruits PP1 $\gamma$ to chromatin and is essential for cell viability. J. Cell Biol. 172: 679-692.

Wei, Y., Mizzen, C.A., Cook, R.G., Gorovsky, M.A., and Allis, C.D. 1998. Phosphorylation of histone $\mathrm{H} 3$ at serine 10 is correlated with chromosome condensation during mitosis and meiosis in Tetrahymena. Proc. Nat1. Acad. Sci. 95: 7480-7484.

Winter, S., Simboeck, E., Fischle, W., Zupkovitz, G., Dohnal, I., Mechtler, K., Ammerer, G., and Seiser, C. 2008. 14-3-3 proteins recognize a histone code at histone $\mathrm{H} 3$ and are required for transcriptional activation. EMBO J. 27: 88-99.

Yang, Y., He, Q., Cheng, P., Wrage, P., Yarden, O., and Liu, Y. 2004. Distinct roles for PP1 and PP2A in the Neurospora circadian clock. Genes \& Dev. 18: 255-260.

Zhang, X., Yang, Z., Khan, S.I., Horton, J.R., Tamaru, H., Selker, E.U., and Cheng, X. 2003. Structural basis for the product specificity of histone lysine methyltransferases. Mol. Cell 12: 177-185.

Zhang, W., Deng, H., Bao, X., Lerach, S., Girton, J., Johansen, J., and Johansen, K.M. 2006. The JIL-1 histone H3S10 kinase regulates dimethyl H3K9 modifications and heterochromatic spreading in Drosophila. Development 133: 229-235.

Zhang, K., Mosch, K., Fischle, W., and Grewal, S.I. 2008. Roles of the Clr4 methyltransferase complex in nucleation, spreading and maintenance of heterochromatin. Nat. Struct. Mol. Biol. 15: 381-388. 


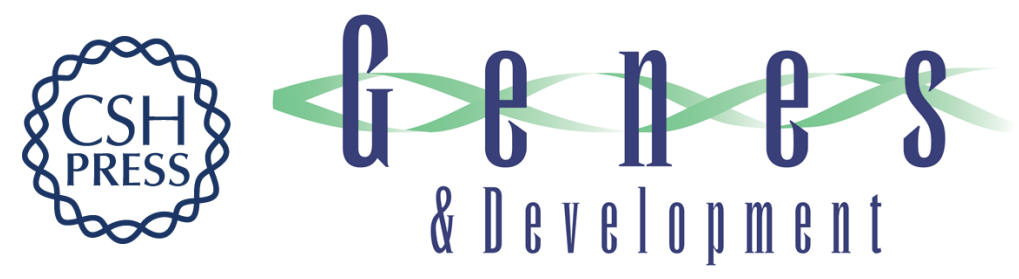

\section{Protein phosphatase PP1 is required for normal DNA methylation in Neurospora}

Keyur K. Adhvaryu and Eric U. Selker

Genes Dev. 2008, 22:

Access the most recent version at doi:10.1101/gad.1738008

\section{Supplemental http://genesdev.cshlp.org/content/suppl/2008/12/15/22.24.3391.DC1 \\ Material}

Related Content

Talk is cheapcross-talk in establishment, maintenance, and readout of chromatin modifications

Wolfgang Fischle

Genes Dev. December , 2008 22: 3375-3382

References This article cites 43 articles, 18 of which can be accessed free at: http://genesdev.cshlp.org/content/22/24/3391.full.html\#ref-list-1

Articles cited in:

http://genesdev.cshlp.org/content/22/24/3391.full.html\#related-urls

\section{License}

Email Alerting

Service

Receive free email alerts when new articles cite this article - sign up in the box at the top right corner of the article or click here.

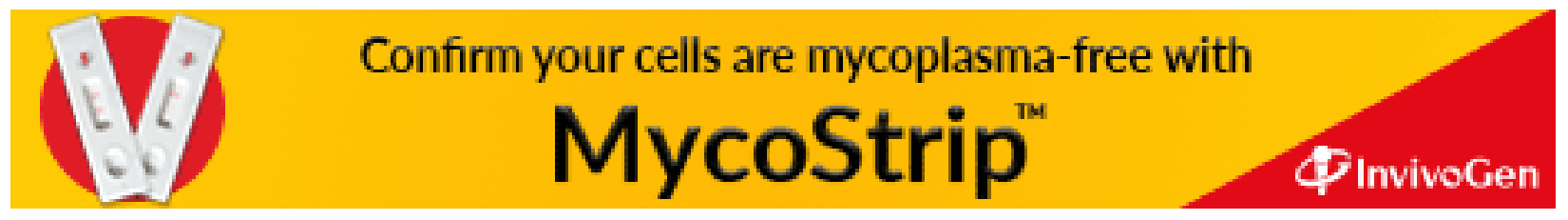

